\title{
Chagas' disease: study of congenital transmission in cases of acute maternal infection
}

\author{
Doença de Chagas: estudo da transmissão congênita nos casos \\ da infecção materna aguda
}

\author{
Edgardo Moretti' ${ }^{1}$ Beatriz Basso', Irma Castro ${ }^{1}$, Mario Carrizo Paez $^{2}$, Marcela Chaul', \\ Gustavo Barbieri ${ }^{3}$, Dámaso Canal Feijoo ${ }^{3}$, María José Sartori ${ }^{4}$ \\ and Rubén Carrizo Paez
}

\begin{abstract}
We studied three pregnant women with acute chagasic infection. Two patients, infected in the third trimester of pregnancy, had uninfected children. The third patient, infected earlier, had an infected newborn. These results encourage research on risk factors of transmission and on medical decisions concerning pregnant women with acute Chagas' disease.
\end{abstract}

Key-words: Chagas' disease. Trypanosoma cruzi. Congenital infection. Acute maternal Trypanosoma cruzi infection.

\section{RESUMO}

Se descrevem 3 gestantes com a doença de Chagas aguda. Duas gestantes infetadas no 3 o trimestre de gestação não tiveram crianças infetadas. $03^{0}$ filho, doquella madre foi infetada no $1^{0}$ trimestre, nasceu com doença de Chagas congénita. Estes resultados inducem a investigação sobre os fatores de riscos da transmição e sobre as desições médicas na conducção dos casos de gestantes com a doença de Chagas aguda.

Palavras-chaves: Doença de Chagas. Trypanosoma cruzi. Infecção congênita. Infecção materna aguda.

Chagas' disease is one of the most important parasitic endemic diseases in Latin America, where near 20 million people are infected and 60 million are at risk of infection. Due to the efforts to carry out vector control in several countries, the transmission through the insect bite, the main epidemiological way of infection, is decreasing, at least in Brazil, Uruguay, Chile and Argentina. Indeed, some of these countries, and some provinces of other countries have been declared free of vector transmission by the Pan American Health Organization. Therefore, nowadays congenital transmission has become more important. In fact, it is estimated that in Argentina the congenital cases are at least 10 times more frequent than the acute cases by vector transmission ${ }^{5}$. Because of migration of people from endemic countries, in the United States there were reported cases of infection, probably by blood transfusion or congenital transmission ${ }^{6}$.
Our group has performed several studies on congenital Chagas' disease, and has proposed a protocol for diagnosis and treatment ${ }^{8}{ }^{9}$. Moreover, several experimental studies have been done in an attempt to determine the possible mechanisms involved in congenital transmission, taking into account that only 2 to $10 \%$ of infected mothers transmitted the infection to their babies ${ }^{411}$. Nevertheless, to date little is known about the factors involved in vertical transmission in humans. There has been speculation about parasitic factors, such as the strain of T. cruzi or the parasitic load, and about host factors, such as immunological or nutritional status of pregnant women, obstetrical history and maternal stage of disease $^{2}$ but none of these factor have been conclusively demonstrated yet. Epidemiological surveys and studies about possible mechanisms of congenital Chagas' disease have been conducted in mothers in the indeterminate or chronic period of infection.

1. Departamento Diagnóstico y Tratamiento del Servicio Nacional de Chagas, Córdoba, Argentina. 2. Hospital Rawson, San Juan, Argentina. 3. Centro de Chagas y Patología Regional, Santiago del Estero. 4. II Cátedra de Biologia Celular, Facultad de Ciencias Médicas, Universidad Nacional de Córdoba, Argentina.

This work was supported by funds from Servicio Nacional de Chagas and SECYT, Universidad Nacional de Córdoba.

Address to: Dr. Edgardo Moretti. Güemes 383, 5000 Córdoba, Argentina

Tel: 54351 422-2424

e-mail: ebi@fcm.unc.edu.ar, or emoretti@hospital-italiano.com.ar

Recebido para publicação em 19/7/2004

Aceito em 14/9/2004 
In this communication, we report clinical, parasitological and serological patterns of three cases of mother-child in which acute Chagas' infection during pregnancy was detected, as well as the presence or absence of infection among the newborns.

\section{CASE REPORTS}

The study group included three pregnant women infected during pregnancy and their babies. Diagnosis of the maternal infection was made by clinical, epidemiological and parasitological parameters. The parasitological methods used were the microhematocrit centrifuge technique, as described by Woo ${ }^{12}$, Strout and hemocultures, essentially performed as previously described in our laboratory'. The classical serological methods (ELISA, Indirect Immunofluorescence and Indirect Hemagglutination were performed for immunodiagnosis. For histological examination, the placenta was fixed with 10\% formaldehyde for $24 \mathrm{~h}$, dehydrated with alcohol/xylol, embedded in paraffin and stained with hematoxylin-eosin.

Case 1. A 30-year-old pregnant woman, accidentally infected while manipulating T. cruzi in a research laboratory. She was at the $32^{\text {nd }}$ week of pregnancy when she became infected, and developed severe acute Chagas' disease, with fever, hepatosplenomegaly and schizotrypanids. Parasitemia was high, detectable through direct blood examination. Due to the severity of the clinical course, the patient required hospitalisation in the intensive care unit and it was necessary to anticipate parturition. Cesarean delivery was indicated at 35 weeks of pregnancy according to clinical, obstetric, and therapeutic criteria. Therapy with benznidazole was successfully applied to the mother immediately after delivery.

In spite of the high parasitemia and the severe clinical course presented by the mother, the newborn - a male infant weighing $3.7 \mathrm{~kg}$ - was not infected, as demonstrated by the absence of circulating parasites and antibodies at birth and until the twelfth month of life. The parasitemia was serially studied by hemoculture, a methodology that previously proved to have near $100 \%$ sensitivity in congenital and acute cases. All the serology tests were negative up to 12 months.

Case 2. A17-year-old woman, infected by vector transmission, in whom the acute infection was clinically diagnosed by ophthalmic ganglionar complex (Figure 1A), and was parasitologically confirmed by the detection of circulating parasites by microhematocrit technique at the $28^{\text {th }}$ week of pregnancy. The clinical course of the disease was mild, and the patient was controlled on an outpatient basis. The delivery took place at 38 weeks of pregnancy, by cesarean section. In this case, histological studies of the placenta were performed, and amastigote forms of T. cruzi were detected in the free chorionic villi (Figure 1B), as well as along the decidua plate. The following microscopic alterations were observed in the placenta: granulomatous changes, inflammatory infiltrates and focal necrosis in the

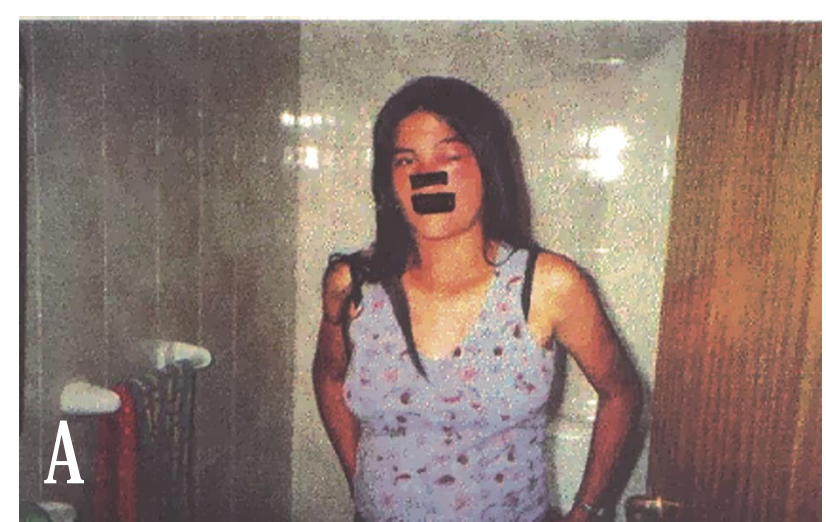

Figure 1A - Pregnant woman (case 2) at 28 weeks of pregnancy, showing ophtalmic ganglionar complex, typical sign of acute Chagas disease.

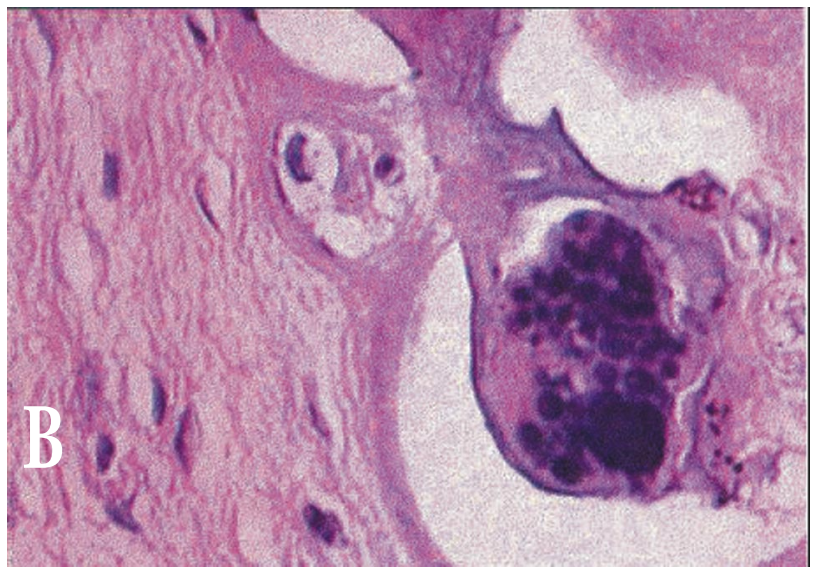

Figure 1B - Histologycal section of placenta (case 2), stained with hematoxylin-eosin, showing amastigote forms of Trypanosoma cruzi (400x).

chorionic villi. The fibrinoid layer was thicker in some modified villi in which syncytial modifications such as edema and calcification foci were present. Vascular thromboses were also seen.

The newborn was a female infant weighting $3.4 \mathrm{~kg}$, and did not present clinical symptoms of Chagas' infection. The absence of infection was confirmed by the fact that the parasitological examinations of cord blood - both by microstrout and hemoculture methods - were negative at birth, and also at the $6^{\text {th }}$ month of life. The infant also have negative serology during the first year of life. Treatment with benznidazole was administrated to the mother after delivery.

Case 3. A19-year-old woman, in whom the acute infection was clinically and parasitologically diagnosed by ophthalmic ganglionar complex and circulating parasites detected during the 20th week of pregnancy. The maternal infection occurred by vector inoculation. The clinical course of disease was mild, and the patient was controlled on an outpatient basis. The baby was born by vaginal delivery at 38 weeks of gestation, with a weight of $3.1 \mathrm{~kg}$, with hepatosplenomegaly, and positive parasitemia and serology. Both, the mother and the newborn were treated with Benznidazole immediately after delivery, and examined through parasitological and serological methods. Sera collected during the longitudinal follow-up of the baby 
Table 1 - Clinical, parasitological and serological results of infected mothers and newborns.

\begin{tabular}{|c|c|c|c|c|c|c|c|c|c|c|}
\hline \multirow[t]{2}{*}{ Case } & \multirow[t]{2}{*}{ Age } & \multirow{2}{*}{$\begin{array}{l}\text { Week of } \\
\text { infection }\end{array}$} & \multirow{2}{*}{$\begin{array}{l}\text { Week of } \\
\text { delivery }\end{array}$} & \multirow{2}{*}{$\begin{array}{c}\text { Clinical } \\
\text { symptoms }\end{array}$} & \multirow{2}{*}{$\begin{array}{l}\text { Type of } \\
\text { delivery }\end{array}$} & \multicolumn{3}{|c|}{ Mother } & \multicolumn{2}{|c|}{ Newborn } \\
\hline & & & & & & parasitology & serology & placenta & parasitology & serology \\
\hline 1 & 30 & 32 & 35 & severe & cesarea & positive & doubtful & ND* & negative & negative \\
\hline 2 & 17 & 28 & 38 & mild & cesarea & positive & doubtful & positive & negative & negative \\
\hline 3 & 19 & 20 & 38 & mild & vaginal & positive & positive & $\mathrm{ND}$ & positive & positive \\
\hline
\end{tabular}

became negative for Trypanosoma cruzi as determined by the same serological tests, at 7 months of age. The parasitological test for parasites was negative, as well.

Table 1 summarizes the main clinical, parasitological and serological findings in the three infected mothers and their babies.

\section{DISCUSSION}

The incidence of congenital transmission has always been determined in women during the indeterminate or chronic period of infection ${ }^{27}$. During these phases of the disease, the parasitemia is low and recurrent, undetectable by direct parasitological methods and only detectable in some cases by xenodiagnosis or hemoculture. There are few previous reports on acute infection of pregnant woman. In fact, Rassi et a ${ }^{10}$ in 1958 in Brazil, reported a case, then reviewed by Brabin ${ }^{3}$. In the present work we studied three acute cases in pregnant women, with high parasitemia and, at least in one of those cases, placental infection and severe histological changes. Taken together, the lack of congenital infection in two of the three studied cases, suggests that the parasitic load does not seem to be a main factor involved in the maternal-fetal transmission of T. cruzi, at least during acute infection of the mother. Moreover, in case 2, the only one in which it was possible to study the placenta, the presence of amastigotes and the severe histological changes were not associated with fetal infection, results that are in agreement with Rassi et $\mathrm{al}^{10}$ and Moya et $\mathrm{al}^{7}$, who reported that placental infection is not synonymous with fetal infection. Even though we studied only three cases, it is interesting to note that in both non-infected cases the maternal infection took place during the third trimester of pregnancy, while in the case in which the newborn was infected, the infection occurred in the earlier period of pregnancy. This finding suggests that the time of infection could be a risk factor for T. cruzi transmission, in the acute infection of the mother. On the other hand, it should not be discarded that, as in other bacterial or viral infections, the transmission could also take place at the moment of delivery. In this sense, in our previous experience ${ }^{8}$ we have found babies who were parasitologically negative at birth and who became positive at 10-15 days of life; with no possibility of other possible forms of transmission.
Finally, as specific antiparasite therapy can not be administrated during pregnancy with the available drugs, it will be necessary to discuss possible medical and therapeutic decisions in pregnant women with acute chagasic infection.

\section{ACKNOWLEDGEMENTS}

We thank Dr. Pedro Moya and Dr. Sofía Parissi de Fabro for their important suggestions and Ms. Patricia Gil for her technical collaboration. This work was supported by funds from Servicio Nacional de Chagas and SECYT, Universidad Nacional de Córdoba.

\section{REFERENCES}

1. Basso B, Moretti E. Detección del Trypanosoma cruzi por hemocultivo en pacientes con Enfermedad de Chagas crónica. Medicina (Buenos Aires) 44:41-47, 1984.

2. BittencourtAL. Possible risk factors for vertical transmission of Chagas' disease. Revista do Instituto de Medicina Tropical de São Paulo 34:403-408, 1992.

3. Brabin L. The epidemiological significance of Chagas disease in women. Memórias do Instituto Oswaldo Cruz 87:73, 1992.

4. Fretes RE, Fabro SP. In vivo and in vitro analysis of lysosomes and acid phosphatase activity in human chagasic placentas. Experimental and Molecular Pathology 63: 153-160, 1995.

5. Gürtler RE, Segura EL, Cohen JE. Congenital transmission of Trypanosoma cruzi infection in Argentina. Emergency Infectious Diseases 9:29-35, 2003.

6. Kirchhoff L. American trypanosomiasis (Chagas' disease). A tropical disease now in the United States. New England Journal Medicine 329:639-644, 1993.

7. Moya P, Moretti E. Doenca de Chagas congenita. In: Fundação do Instituto Oswaldo Cruz. "Clinica e Terapeutica da doenca de Chagas: Uma abordagem pratica para 0 clinico geral". $1^{\text {st }}$ edition, Rio de Janeiro p. 383-410, 1997.

8. Moya P, Moretti E, Paolasso R, Basso B, Blanco S, Sanmartino C. Enfermedad de Chagas neonatal. Diagnostico de Laboratorio durante el primer año de vida. Medicina (Buenos Aires) 49:595-599, 1989.

9. Moya P, Paolasso R, Blanco S, Lapacet M, Sanmartino C, Basso B, Moretti E, Cura D. Enfermedad de Chagas: Resultados terapéuticos en niños en los primeros meses de vida. Medicina (Buenos Aires) 45:553-558, 1985.

10. Rassi A, Borges C, Koeberle F, De Paula OH. Sobre a transmissão congênita da doença de Chagas. Revista Goiania de Medicina 4:319-332, 1958.

11. Sartori MJ, Lin S, Frank FM, Malchiodi E, Fabro SP. The role of placental alkaline phosphatase in the interaction between human placental Trophoblast and Trypanosoma cruzi. Experimental and Molecular Pathology 72: 84-90, 2002.

12. Woo PT. The haematocrit centrifuge technique for the detection of trypanosomes in blood. Canadian Journal Zoology 47:921-924, 1969. 